\title{
MALIGNANT HYPERTENSION DUE TO PHAEOCHROMOCYTOMA IN A CHILD
}

\author{
BY \\ F. E. HIGGINS \\ From the Department of Medicine, General Infirmary at Leeds
}

(RECEIVED FOR PUBLICATION DECEMBER 17, 1956)

The case reports of phaeochromocytoma in children have recently been reviewed by Smid and DuShane (1955) who were able to collect details of 32 cases. Since their account further instances have been published by Robinson and Williams (1956) and Mégevand and Ferrier (1954). A further successful case is reported here. Including the present patient, 36 children have been affected; of these, 26 have been subjected to surgery and 18 have survived.

\section{Case Report}

The patient was 11 years old when first seen in the Out-patient Department. His mother said that he had enjoyed good health until the age of 8 when he seemed to have stopped growing and was gradually overtaken in height and weight by a younger brother. At the same age the patient began to sweat excessively. Initially the attacks were intermittent and more severe at night, but in more recent months he seemed to perspire to some degree almost continuously. For 12 months he had been unable to play games because of exertional dyspnoea and for four months before admission had complained of occasional frontal headache and vomiting. His vision was not affected. He was admitted to the General Infirmary at Leeds for further investigation on December 13, 1955.

On examination he was small for his age but normally proportioned (height $49 \mathrm{in}$. and weight $60 \mathrm{lb}$.). His face was pale and he had an anxious expression. Both hands were red and swollen due to a firm non-pitting oedema which extended as far as the wrists. There was no desquamation of the skin but the general appearance strongly resembled that seen in pink disease in infants. The feet were not so affected. The blood pressure varied from $240 / 130 \mathrm{~mm}$. of mercury to $280 / 160 \mathrm{~mm}$. of mercury. All peripheral pulses were present and equal. The resting pulse rate was 100 per minute. Neither changes in posture nor loin massage had any effect on the blood pressure. The heart was not enlarged. The cardiac impulse was forceful and the aortic second sound accentuated. A few fine rales were present at both lung bases. There was no evidence of congestive heart failure. Examination of the fundi revealed bilateral papilloedema with numerous linear haemorrhages and soft exudates. No abdominal tumour was palpable. The urine occasionally contained a trace of albumin. There was no glycosuria.

A blood count gave: R.B.C. $5 \cdot 2$ m., Hb $106 \%$, W.B.C. 15,800 with a normal differential. The fasting blood sugar was $120 \mathrm{mg}$. \%. A mid-stream specimen of urine was sterile on culture and no cells or casts were seen. The blood urea nitrogen was $16 \mathrm{mg}$. \%. The urea clearance test was within normal limits. The serum sodium, potassium, chloride, $\mathrm{CO}_{2}$-combining power were all within normal limits. The chest radiographs showed a heart of normal size and the lung fields were clear. An intravenous pyelogram showed that both kidneys concentrated the dye well and the calyceal pattern was normal.

For perirenal air insufflation (Dr. D. A. W. Cowie) approximately $400 \mathrm{ml}$. of air was used, and tomographs were made. On the left a good outline was secured and no abnormal mass of adrenal tissue could be seen. On the right side there did appear to be a larger suprarenal opacity.

An E.C.G. showed some ST segment depression in leads V5, V6, but was otherwise within normal limits.

An assay of the urinary excretion of catechol amines was done at University College Hospital. The preoperative 24-hour specimen of $1,000 \mathrm{ml}$. contained approximately $1 \mu \mathrm{g}$. noradrenaline per $\mathrm{ml}$. and was indicative of phaeochromocytoma. (The output of noradrenaline in normal adult urine is less than $63 \mu \mathrm{g} . / 24$ hours (von Euler, 1954). In essential hypertension the daily excretion of pressor amines is usually less than $100 \mu \mathrm{g}$. but occasionally as much as $200 \mu \mathrm{g}$./ 24 hours (von Euler, 1952). Most patients with phaeochromocytoma excrete more than $250 \mu \mathrm{g}$. of pressor amines daily.)

Rogitine (phentolamine), $1.5 \mathrm{mg}$. given intravenously, reduced the blood pressure from $210 / 150$ to $135 / 110$ mm.Hg (Fig. 1).

On January 1, after a hypertensive crisis, the boy developed a minimal left hemiparesis. Any further pre-operative studies were therefore abandoned. For 48 hours before operation he was given 'rogitine' intramuscularly in doses of $1.5 \mathrm{mg}$. at intervals dictated by the blood pressure responses. On January 4 , by an 
intrathoracic approach and removal of the tenth rib: Mr. H. Shuckmsith removed the right adrenal gland, This incorporated a firm tumour $4.5 \mathrm{~cm}$. in diameter. The pathological report on the tumour was as follows.

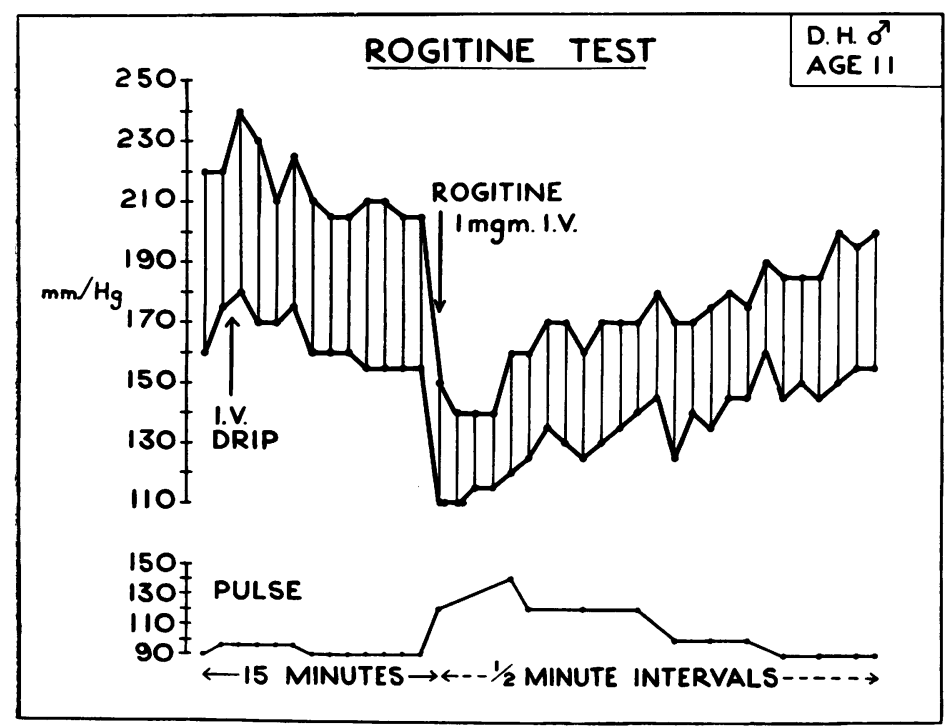

FIG. 1.

'The specimen is an adrenal gland distorted by an ovoid solid circumscribed tumour $4 \times 3 \cdot 5 \times 3 \mathrm{~cm}$. with a purple brown cut surface. The tumour appears to be growing outwards from the interior of the gland stretching and thinning the cortex which overlies it. After photography part of the tumour was refixed in bichromate and developed a brownish colour.

The tumour is composed of sheets of syncytial masses of pleomorphic cells. Many have round vesicular nuclei and vesicular cytoplasm resembling cells of the cortex. Others have extremely large deeply basophilic reticular nuclei and no recognizable cytoplasmic boundary. Thin-walled, dilated blood vessels are a feature and there are areas of haemorrhage and degeneration. Sections of bichromate-fixed material show numerous brown chromaffin granules in many of the cells. This is a typical phaeochromocytoma; nothing in the appearance suggests malignant change (Dr. I. Dawson).'

During the induction of anaesthesia, and until the tumour was excised, the blood pressure was controlled by intermittent intravenous 'rogitine' (phentolamine) in accordance with the technique outlined by Helps, Robinson and Ross (1955). After the removal of the tumour the blood pressure was maintained by intravenous noradrenaline and a satisfactory pressure response obtained at a dose of $25 \mu \mathrm{g}$. per minute. This concentration was gradually reduced and the infusion discontinued seven hours post-operatively (Fig. 2).

Convalescence was uneventful. A moderate hypertension of $110 \mathrm{~mm}$. of mercury diastolic persisted for two weeks and then the pressure returned to normal. A second specimen of urine for pressor amines on the thirteenth post-operative day contained less than $0.1 \mu \mathrm{g}$. per $\mathrm{ml}$. (within normal limits).

During the course of a 7-month follow-up the boy has had a normal blood pressure and the changes of malignant hypertensive retinopathy have regressed completely. Growth, which seemed to have been arrested at about the eighth year, has been resumed. He has gained 1 in. in height and $10 \mathrm{lb}$. in weight.

\section{Discussion}

Daeschner, Moyer and Able (1954) have reviewed the clinical features of phaeochromocytoma in children. Although tumours occur at all ages the average age of paediatric cases has been 10 years at the time of diagnosis. Symptoms, however, have usually been present for two years. The hyperten-

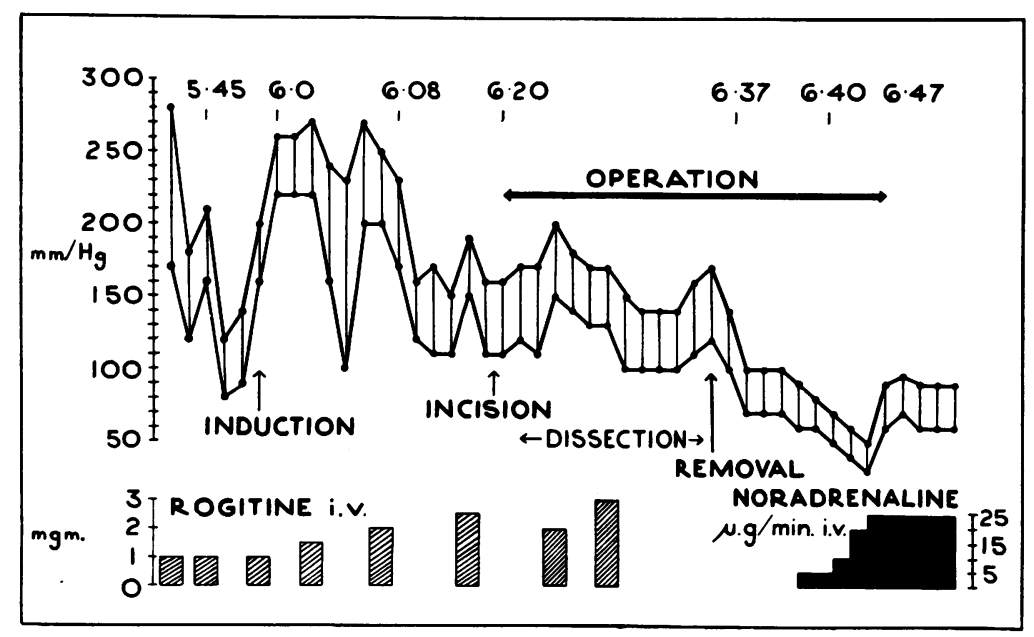

FIG. 2. 
sion is usually sustained, malignant retinopathy and sweating are common. Renal function is unimpaired. The hands and feet may resemble acrodynia and it is of interest that recent studies by Farquhar, Crawford and Law (1956) suggest that urinary sympathin secretion may be raised in pink disease. While growth may be retarded by many types of serious illness in childhood this seems to be the first case of phaeochromocytoma in which arrest of growth was such a prominent feature.

\section{Summary}

The patient described stopped growing at the age of 8 years and concomitantly developed symptoms suggestive of phaeochromocytoma. When first seen he had malignant hypertension with grade IV hypertensive retinopathy. The diagnosis was confirmed by assay of the urinary excretion of catechol amines which yielded $1 \mu \mathrm{g} . / \mathrm{ml}$. (1,000 $\mu \mathrm{g} . / 24 \mathrm{hr}$.). A right adrenal tumour was successfully removed and growth appears to have been resumed.

I should like to thank Professor R. E. Tunbridge for permission to publish this case and for his helpful criticism; Mr. D. A. Willoughby for estimation of the catechol amine excretion; Sisters $M$. Harrison and $\mathbf{M}$. Thwaites for the excellent management of a difficult nursing problem and Miss Campbell for the reproduction of the blood pressure recordings.

\section{REFERENCES}

Daeschner, C. W., Moyer, J. H. and Able, L. W. (1954). J. Pediat., 45,141 .

Euler, U.S. von (1952). Scand. J. clin. Lab. Invest., 4, 254.

(1954). Pharmacol. Rev., 6, 15.

Farquhar, J. W., Crawford, T. B. B. and Law, W. (1956). Brit. med. J., 2, 276.

Helps, E. P. W., Robinson, K. C. and Ross, E. J. (1955). Lancet, 2,267

Mégevand, A. and Ferrier, S. (1954). Ann. paediat. (Basel), 183, 337. Robinson, M. J. and Williams, A. (1956). Archives of Disease in Childhood, 31, 69

Smid, A. C. and DuShane, J. W. (1955). Amer. Dis. Child., 90, 81. 